\title{
Model przestrzenny pionowego spiralnego przenośnika wibracyjnego
}

\author{
Grzegorz Cieplok $^{1}$ iD, Piotr Chyła ${ }^{1}$ (D), \\ Cezary Kasprzak $^{1}$ iD, Dariusz Cichoń ${ }^{2}$ \\ 1 AGH Akademia Górniczo-Hutnicza, Wydział Inżynierii Mechanicznej i Robotyki, Kraków \\ 2 AGH Akademia Górniczo-Hutnicza, Wydział Zarządzania, Kraków
}

Streszczenie: W pracy przedstawiono budowę modelu przestrzennego pionowego spiralnego przenośnika wibracyjnego o napędzie bezwładnościowym. Model uwzględnia wzajemne sprzężenie korpusu przenośnika i wibratorów bezwładnościowych, co umożliwia odzwierciedlenie zjawiska samosynchronizacji mas niewyważonych. Na podstawie parametrów przykładowego przenośnika przedstawiono badania symulacyjne obejmujące rozruch, stan pracy ustalonej oraz wybrane przypadki pracy awaryjnej. Zaprezentowany w pracy model może stanowić uzupełnienie istniejących do tej pory modeli o jednym stopniu bądź dwóch stopniach swobody.

Słowa kluczowe: przenośnik wibracyjny, transport pionowy, model przestrzenny, kąty Eulera

\section{THE SPATIAL MODEL OF VERTICAL SPIRAL VIBRATING CONVEYOR}

\begin{abstract}
The paper presents the construction of a spatial model of a vertical spiral vibrating conveyor with inertial drive. The model takes into account the mutual coupling of the conveyor body and inertial vibrators to reflect the phenomenon of self-synchronisation of unbalanced masses. On the basis of the parameters of the exemplary conveyor, simulation tests were presented, including start-up, steady state operation and selected cases of emergency operation. The model presented in the paper may complement the existing models with one or two degrees of freedom.
\end{abstract}

Keywords: vibrating conveyor, vertical transport, spatial model, Euler

https://doi.org/10.7494/978-83-66727-47-2_3 


\section{Wstęp}

Pionowe wibracyjne przenośniki spiralne o napędzie bezwładnościowym są urządzeniami powszechnie wykorzystywanymi w transporcie materiałów sypkich (Czubak 2013), lekkich, w tym abrazyjnych. Należą do urządzeń bezawaryjnych, cichych w eksploatacji, o płynnym ruchu materiału. W trakcie działania umożliwiają realizowanie dodatkowych procesów fizycznych, takich jak suszenie, studzenie, nagrzewanie, nawilżanie czy przewietrzanie materiału.

Składają się zasadniczo z trzech części (rys. 1): pionowej rynny o kształcie helisy i zazwyczaj prostokątnym przekroju poprzecznym, układu dwóch wibratorów bezwładnościowych wprowadzających w drgania korpus przenośnika (Michalczyk i in. 2006, Bayıroğlu 2015) i sprężystego zawieszenia. Zawieszenie może być wykonane w postaci układu sprężyn śrubowych (Michalczyk i Bera 2019), wibroizolatorów stalowo-elastomerowych (Sikora et al. 2018) lub listew stalowych. W tym ostatnim przypadku układu o własnościach kierunkowych.

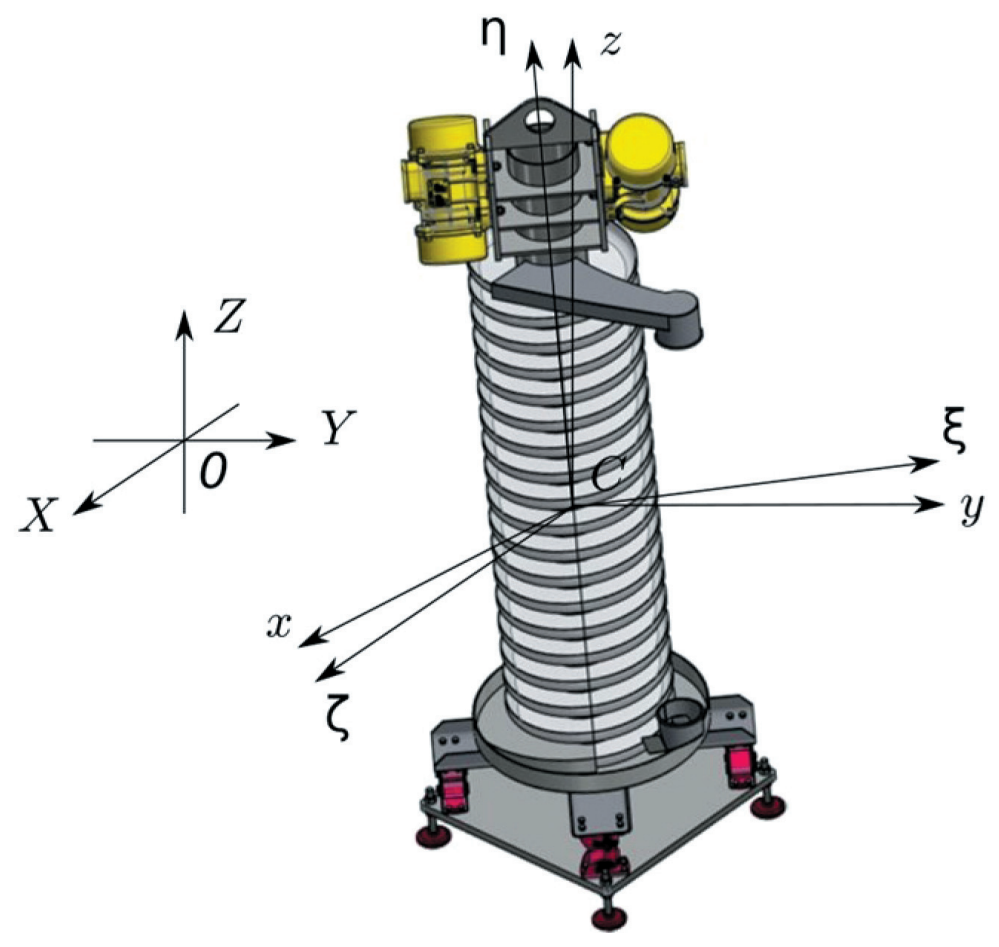

Rys. 1. Podnośnik wibracyjny spiralny OVIBRA: $0 X Y Z$ układ bazowy - nieruchomy, Cxyz układ związany ze środkiem masy przenośnika i równoległy do $0 X Y Z, C \xi \eta \zeta-$ układ związany z głównymi centralnymi osiami bezwładności przenośnika

Źródło: https://ovibra.eu/podajniki-wibracyjne-bezwladnosciowe (za zgodą KMC Global) 
Ruch przenośnika jest ruchem ogólnym z wyraźną przewagą drgań pionowych i obrotowych wokół pionowej osi korpusu. Złożenie tych ruchów kreuje trajektorię umożliwiającą transportowanie materiału wzdłuż rynny przenośnika w kierunku pionowym.

Chociaż projektowanie przenośników tego typu nie nastręcza konstruktom trudności, to istnieje ciągła potrzeba udoskonalania ich modeli i programów symulacyjnych. Potrzeba ta jest związana przede wszystkim z faktem, iż istniejące opisy oparte są na modelach uproszczonych, wynikających tylko z rozpatrzenia złożenia ruchu prostoliniowego korpusu przenośnika wzdłuż kierunku pionowego oraz ruchu obrotowego dookoła jego osi pionowej. W rzeczywistości przenośnik wykonuje znacznie bardziej złożony ruch, którego konsekwencje uwidaczniają się w przypadku stanów przejściowych i awaryjnych.

Modele uproszczone (Hamed i in. 2017, Su 2019) nie mogą odzwierciedlić również bardzo istotnego ze względu na prawidłowe działanie przenośnika zjawiska samosynchronizacji wibratorów bezwładnościowych. Niedostatecznie silna synchronizacja wibratorów prowadzi do przesunięć fazowych sił wymuszających i powstania sił i momentów niepożądanych, zaburzających zakładany ruch rynny przenośnika.

W związku z powyższym budowa modelu przestrzennego staje się uzasadniona.

\section{Model matematyczny}

W pracy Cieploka i Wójcik (2020) przedstawiono zmodyfikowany układ kątów Eulera szczególnie wygodny do opisu ruchu bryły posadowionej na zawieszeniu sprężystym. W takim przypadku, w zakresie małych przemieszczeń kątowych ciała, kąty Eulera w dobrym przybliżeniu odpowiadają obrotom bryły względem trzech osi prostokątnego układu współrzędnych (rys. 2). Zależności pomiędzy współrzędnymi punktu P w układzie $C \xi \eta \zeta$ a współrzędnymi tego punktu w układzie $C x y z$ przedstawia transformacja (1). Transformacja ta może być również stosowana do przeliczenia składowych wektora pomiędzy układami:

$$
\left[\begin{array}{l}
x_{P} \\
y_{P} \\
z_{P}
\end{array}\right]=\left[\begin{array}{ccc}
\cos \Psi \sin \phi \sin \theta-\sin \Psi \cos \varphi & \cos \Psi \cos \varphi \sin \theta & \cos \Psi \cos \theta \\
\sin \Psi \sin \varphi \sin \theta+\cos \Psi \cos \varphi & \sin \Psi \cos \varphi \sin \theta-\cos \Psi \sin \varphi & \sin \Psi \cos \theta \\
\sin \varphi \cos \theta & \cos \varphi \cos \theta & -\sin \theta
\end{array}\right]\left[\begin{array}{c}
\xi_{P} \\
\eta_{P} \\
\zeta_{P}
\end{array}\right]
$$

W przypadku ruchu korpusów maszyn wibracyjnych, dla których można przyjąć małe przemieszczenia kątowe, przekształcenie (1) można znacznie uprościć. Przyjmując przybliżenia $\sin (\alpha) \approx \alpha, \cos (\alpha) \approx 1$ oraz pomijając małe rzędu wyższego 
niż dwa, można przesunięcie punktu $\mathrm{P}$ w układzie bazowym $0 X Y Z$ zapisać w postaci zależności:

$$
\left[\begin{array}{l}
\delta x_{P} \\
\delta y_{P} \\
\delta z_{P}
\end{array}\right]=\left[\begin{array}{cccccc}
1 & 0 & 0 & -\xi_{P} & \eta_{P} & 0 \\
0 & 1 & 0 & \zeta_{P} & 0 & -\eta_{P} \\
0 & 0 & 1 & 0 & -\zeta_{P} & \xi_{P}
\end{array}\right]\left[\begin{array}{c}
x_{C} \\
y_{C} \\
z_{C} \\
\Psi \\
\theta \\
\varphi
\end{array}\right]
$$

gdzie:

$x_{C}, y_{C}, z_{C}-$ przesunięcia punktu $\mathrm{C}$ w układzie bazowym $0 X Y Z$, $\Psi, \theta, \varphi$ - kąty Eulera mierzone względem układu $C x y z$, $\xi_{P}, \eta_{P}, \zeta_{P}-$ współrzędne punktu $\mathrm{P}$ w układzie $C \xi \eta \zeta$.

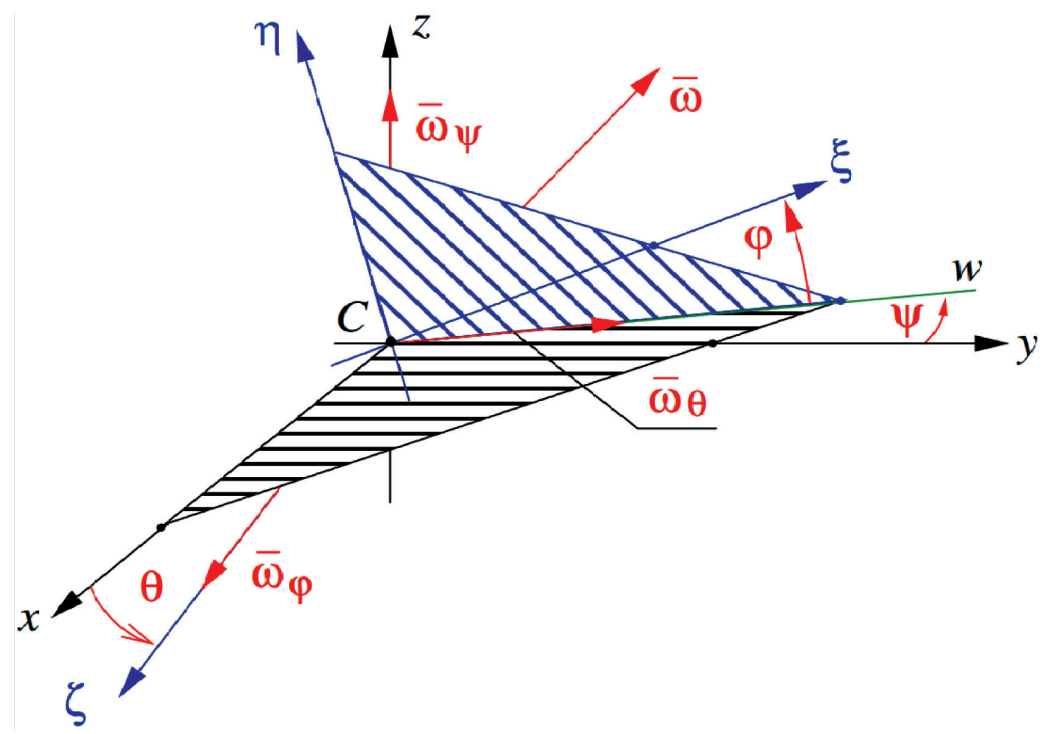

Rys. 2. Zmodyfikowany układ kątów Eulera po obrotach o $\theta=\frac{\pi}{2}, \Psi=\frac{\pi}{2}$

\subsection{Energia kinetyczna korpusu}

Korpus podajnika wykonuje ruch ogólny. Jego energię kinetyczną możemy zapisać jako sumę energii ruchu postępowego z prędkością środka masy korpusu i energii ruchu kulistego dookoła jego środka masy:

$$
E_{k}=\frac{1}{2} m_{k} \dot{x}_{C}^{2}+\frac{1}{2} m_{k} \dot{y}_{C}^{2}+\frac{1}{2} m_{k} \dot{z}_{C}^{2}+\frac{1}{2} J_{\xi} \omega_{\xi}^{2}+\frac{1}{2} J_{\eta} \omega_{\eta}^{2}+\frac{1}{2} J_{\zeta} \omega_{\zeta}^{2}
$$


Na podstawie rysunku 2 składowe prędkości kątowej ciała w rzucie na jego główne centralne osie bezwładności $\xi \eta \zeta$ możemy zapisać jako:

$$
\left[\begin{array}{c}
\omega_{\xi} \\
\omega_{\eta} \\
\omega_{\zeta}
\end{array}\right]=\left[\begin{array}{ccc}
\sin \varphi \cos \theta & \cos \varphi & 0 \\
\cos \varphi \cos \theta & -\sin \varphi & 0 \\
-\sin \theta & 0 & 1
\end{array}\right]\left[\begin{array}{c}
\dot{\Psi} \\
\dot{\theta} \\
\dot{\varphi}
\end{array}\right]
$$

\subsection{Energia kinetyczna wibratorów}

Energię kinetyczną wibratorów możemy wyznaczyć analogicznie jak korpusu, stosując wzór na sumę energii ruchu postępowego i kulistego ciała:

$$
\begin{gathered}
E_{w 1,2}=\frac{1}{2} m_{1} \dot{x}_{C 1}^{2}+\frac{1}{2} m_{1} \dot{y}_{C 1}^{2}+\frac{1}{2} m_{1} \dot{z}_{C 1}^{2}+\frac{1}{2} m_{2} \dot{x}_{C 2}^{2}+\frac{1}{2} m_{2} \dot{y}_{C 2}^{2}+\frac{1}{2} m_{2} \dot{z}_{C 2}^{2} \\
+\frac{1}{2} J_{\xi_{1}} \omega_{\xi 1}^{2}+\frac{1}{2} J_{\eta 1} \omega_{\eta 1}^{2}+\frac{1}{2} J_{\zeta_{1}} \omega_{\zeta_{1}}^{2}+\frac{1}{2} J_{\xi_{2}} \omega_{\xi 2}^{2}+\frac{1}{2} J_{\eta 2} \omega_{\eta 2}^{2}+\frac{1}{2} J_{\zeta_{2}} \omega_{\zeta_{2}}^{2}
\end{gathered}
$$

gdzie: $\omega_{\xi 1}, \omega_{\eta 1}, \omega_{\zeta 1}, \omega_{\xi 2}, \omega_{\eta 2}, \omega_{\zeta 2}$ - rzuty prędkości kątowych wibratorów na ich główne centralne osie bezwładności.

Na podstawie rysunku 3 możemy wyznaczyć współrzędne środków mas wibratorów.

a)

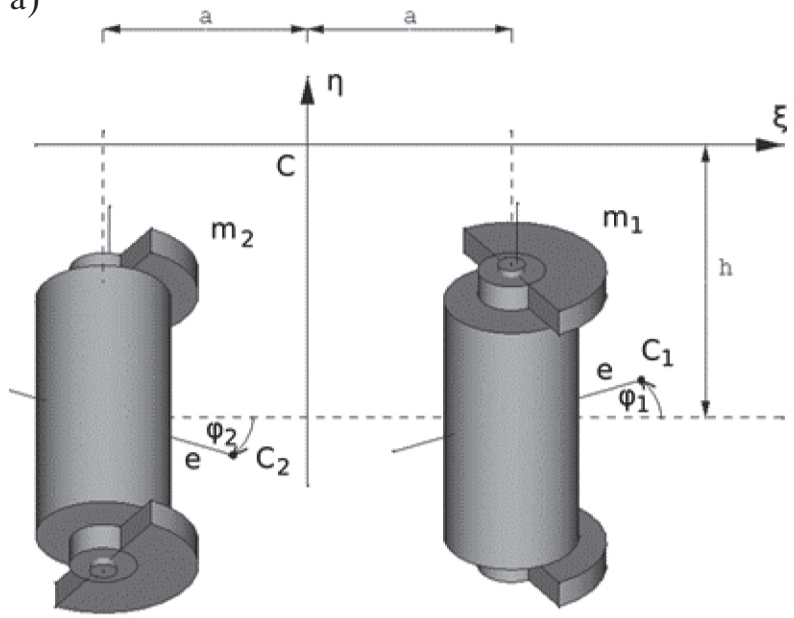

b)

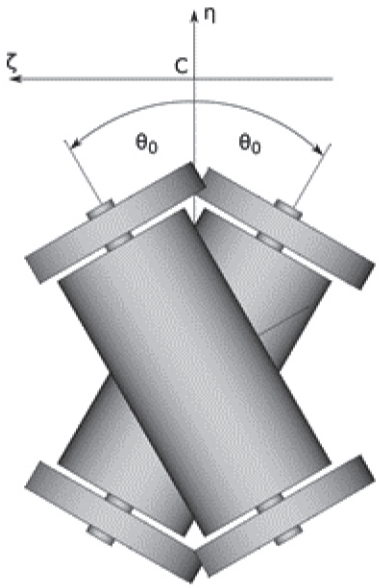

Rys. 3. Położenie wibratorów bezwładnościowych w układzie $C \xi \eta \zeta$ :

a) widok w płaszczyźnie $\xi \eta ;$ b) widok w płaszczyźnie $\zeta \eta$ 
W układzie $C \xi \eta \zeta$ związanym z korpusem i przy przeciwnym kierunku wirowania wibratorów przyjmują one zależności:

$$
\begin{aligned}
& \xi_{C 1,2}=e \cos \left(\varphi_{1,2}\right) \pm a \\
& \eta_{C 1,2}= \pm e \cos \left(\theta_{0}\right) \sin \left(\varphi_{1,2}\right)-h \\
& \zeta_{C 1,2}=e \sin \left(\theta_{0}\right) \sin \left(\varphi_{1,2}\right)
\end{aligned}
$$

Przyjmując małe przemieszczenia kątowe korpusu $\Psi, \eta, \zeta$ (w zakresie jednej setnej radiana), możemy na postawie zależności (2) określić ich położenia w układzie globalnym:

$$
\begin{aligned}
& x_{C 1,2}=-\Psi \cdot \xi_{C 1,2}+\theta \cdot \eta_{C 1,2}+\zeta_{C 1,2}+x_{C} \\
& y_{C 1,2}=\xi_{C 1,2}+\varphi \cdot \eta_{C 1,2}+\Psi \cdot \zeta_{C 1,2}+y_{C} \\
& z_{C 1,2}=\varphi \cdot \xi_{C 1,2}+\eta_{C 1,2}-\theta \cdot \zeta_{C 1,2}+z_{C}
\end{aligned}
$$

Różniczkując zależności względem czasu, otrzymujemy prędkości środków mas wibratorów (8) w funkcji współrzędnych uogólnionych i ich pochodnych niezbędne do określenia zależności (5).

$$
\begin{aligned}
& \dot{x}_{C 1,2}=\dot{\varphi}_{1,2} e \cos \left(\varphi_{1,2}\right) \sin \left(\theta_{0}\right) \pm\left(\dot{\varphi}_{1,2} e \cos \left(\varphi_{1,2}\right) \theta+\dot{\theta} e \sin \left(\varphi_{1,2}\right)\right) \cos \left(\theta_{0}\right) \\
& +\Psi \dot{\varphi}_{1,2} e \sin \left(\varphi_{1,2}\right)-\dot{\Psi} e \cos \left(\varphi_{1,2}\right)-\dot{\theta} h+\dot{x}_{C}-a \dot{\Psi} \\
& \dot{y}_{C 1,2}=\left(\dot{\Psi} e \sin \left(\varphi_{1,2}\right)+\Psi \dot{\varphi}_{1,2} e \cos \left(\varphi_{1,2}\right)\right) \sin \left(\theta_{0}\right) \pm\left(-\dot{\varphi} e \sin \left(\varphi_{1,2}\right)\right. \\
& \left.-\dot{\varphi}_{1,2} e \varphi \cos \left(\varphi_{1,2}\right)\right) \cos \left(\theta_{0}\right)-\dot{\varphi}_{1,2} e \sin \left(\varphi_{1,2}\right)+\dot{\varphi} h+\dot{y}_{C} \\
& \dot{z}_{C 1,2}=\left(-\dot{\varphi}_{1,2} e \cos \left(\varphi_{1,2}\right) \theta-\dot{\theta} e \sin \left(\varphi_{1,2}\right)\right) \sin \left(\theta_{0}\right) \pm \dot{\varphi}_{1,2} e \cos \left(\varphi_{1,2}\right) \cos \left(\theta_{0}\right) \\
& \quad-\dot{\varphi}_{1,2} e \varphi \sin \left(\varphi_{1,2}\right)+\dot{\varphi} e \cos \left(\varphi_{1,2}\right)+\dot{z}_{C}+a \dot{\varphi}
\end{aligned}
$$


Prędkości kątowe poszczególnych wibratorów możemy z kolei określić jako sumę geometryczną prędkości kątowej korpusu i prędkości względnej wibratora względem korpusu - odpowiednio $\dot{\varphi}_{1}$ i $\dot{\varphi}_{2}$. Rzuty tych prędkości na główne osie bezwładności wibratorów mogą zostać zapisane w formie:

$$
\left[\begin{array}{c}
\omega_{\xi 1,2} \\
\omega_{\eta 1,2} \\
\omega_{\zeta 1,2}
\end{array}\right]=\left[\begin{array}{ccc}
\sin \varphi_{1,2} \sin \theta_{0} & \cos \varphi_{1,2} & \pm \sin \varphi_{1,2} \cos \theta_{0} \\
\pm \cos \varphi_{1,2} \sin \theta_{0} & \mp \sin \varphi_{1,2} & \cos \varphi_{1,2} \cos \theta_{0} \\
\cos \theta_{0} & 0 & \mp \sin \theta_{0}
\end{array}\right]\left[\begin{array}{c}
\omega_{\zeta} \\
\omega_{\xi} \\
\omega_{\eta}
\end{array}\right]+\left[\begin{array}{c}
0 \\
0 \\
\pm \dot{\varphi}_{1,2}
\end{array}\right]
$$

gdzie:

$\varphi_{1,2}$ - kąt obrotu wibratora (zależny od czasu),

$\theta_{0}-$ kąt pochylenia osi wibratora (stały w czasie).

Zastępując prędkości $\omega_{\xi}, \omega_{\eta}, \omega_{\zeta}$ zależnościami określonymi wzorem (4), otrzymujemy zależności wyrażone w funkcji współrzędnych i pochodnych uogólnionych:

$$
\begin{aligned}
& \omega_{\xi 1,2}=\dot{\Psi}\left(-\sin \left(\varphi_{1,2}\right) \sin (\theta) \sin \left(\theta_{0}\right) \pm \cos (\varphi) \sin \left(\varphi_{1,2}\right) \cos (\theta) \cos \left(\theta_{0}\right)\right. \\
& \left.+\sin (\varphi) \cos \left(\varphi_{1,2}\right) \cos (\theta)\right)+\dot{\varphi} \sin \left(\varphi_{1,2}\right) \sin \left(\theta_{0}\right) \\
& +\dot{\theta}\left(\cos (\varphi) \cos \left(\varphi_{1,2}\right) \mp \sin (\varphi) \sin \left(\varphi_{1,2}\right) \cos \left(\theta_{0}\right)\right) \\
& \omega_{\eta 1,2}=\dot{\Psi}\left(\mp \cos \left(\varphi_{1,2}\right) \sin (\theta) \sin \left(\theta_{0}\right)+\cos (\varphi) \cos \left(\varphi_{1,2}\right) \cos (\theta) \cos \left(\theta_{0}\right)\right. \\
& \left.\mp \sin (\varphi) \sin \left(\varphi_{1,2}\right) \cos (\theta)\right) \pm \dot{\varphi} \cos \left(\varphi_{1,2}\right) \sin \left(\theta_{0}\right) \\
& +\dot{\theta}\left(-\sin (\varphi) \cos \left(\varphi_{1,2}\right) \cos \left(\theta_{0}\right) \mp \cos (\varphi) \sin \left(\varphi_{1,2}\right)\right) \\
& \omega_{\zeta 1,2}=\dot{\Psi}\left(\mp \cos (\varphi) \cos (\theta) \sin \left(\theta_{0}\right)-\sin (\theta) \cos \left(\theta_{0}\right)\right) \\
& \pm \dot{\theta} \sin (\varphi) \sin \left(\theta_{0}\right)+\dot{\varphi} \cos \left(\theta_{0}\right) \pm \dot{\varphi}_{1,2}
\end{aligned}
$$

\subsection{Energia potencjalna układu}

Korpus maszyny jest podtrzymywany za pomocą układu sprężyn stalowych schematycznie przedstawionych na rysunku 4. 


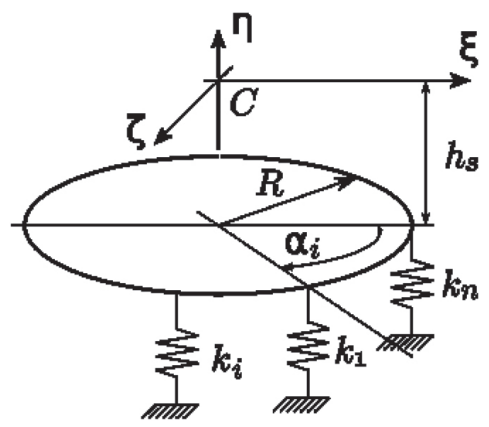

Rys. 4. Sposób ułożenia sprężyn podparcia

Na mocy zależności (2) przemieszczenia końca $i$-tej sprężyny w układzie bazowym możemy wyznaczyć jako:

$$
\begin{aligned}
& \delta x_{i} \cong x_{c}-\Psi R_{\xi_{i}}+h_{s} \theta \\
& \delta y_{i} \cong y_{c}-\varphi h_{s}+\Psi R_{\zeta_{i}} \\
& \delta z_{i} \cong z_{c}+\varphi R_{\xi_{i}}-\theta R_{\zeta_{i}}
\end{aligned}
$$

gdzie:

$$
\begin{aligned}
& R_{\xi_{i}}=R \cos \left(\frac{2 \pi}{n} i\right) \\
& R_{\eta i}=R \sin \left(\frac{2 \pi}{n} i\right)
\end{aligned}
$$

$R$ - promień okręgu wieńca sprężyn, $n$ - liczba sprężyn we wieńcu.

Energia potencjalna związana z pracą sił grawitacji zależna jest od położenia środków mas korpusu i wibratorów w układzie globalnym. Te ostatnie są określone zależnościami (7c).

Sumarycznie energię potencjalną układu możemy przedstawić jako:

$$
V=m_{k} g \cdot z_{C}+m_{1} g \cdot z_{C 1}+m_{2} g \cdot z_{C 2}+\sum_{i=1}^{n}\left(\frac{1}{2} k_{x i} \delta x_{i}^{2}+\frac{1}{2} k_{y i} \delta y_{i}^{2}+\frac{1}{2} k_{z i} \delta z_{i}^{2}\right)
$$

\subsection{Równania ruchu}

Na podstawie wyprowadzonych zależności na energię kinetyczną i potencjalną części układu możemy sformułować funkcję Lagrange’a:

$$
L=E_{k}+E_{w 1,2}-V
$$


i następnie wyznaczyć dynamiczne równania ruchu odpowiednio dla każdej współrzędnej uogólnionej $q_{i}$ :

$$
\frac{d}{d t} \frac{\partial L}{\partial \dot{q}_{i}}-\frac{\partial L}{\partial q_{i}}=Q_{i}
$$

gdzie za $q_{i}$ należy podstawić kolejno: $x_{C}, y_{C}, z_{C}, \Psi, \theta, \varphi, \varphi_{1}, \varphi_{2}$.

Ze względu na rozbudowaną postać równań w niniejszej pracy zaprezentowano tylko jedno z nich - (16), odpowiadające współrzędnej $z_{C}$. W równaniu przyjęto $m_{1}=m_{2}=m_{w}$.

$$
\begin{aligned}
& \left(m_{k}+2 m_{w}\right) \ddot{z}_{C}+m_{w} e\left(\left(\dot{\varphi}_{2}^{2} \sin \left(\varphi_{2}\right)-\ddot{\varphi}_{2} \cos \left(\varphi_{2}\right)+\dot{\varphi}_{1}^{2} \sin \left(\varphi_{1}\right)-\ddot{\varphi}_{1} \cos \left(\varphi_{1}\right)\right) \theta\right. \\
& \left.\quad-\ddot{\theta} \sin \left(\varphi_{2}\right)-2 \dot{\varphi}_{2} \dot{\theta} \cos \left(\varphi_{2}\right)-\ddot{\theta} \sin \left(\varphi_{1}\right)-2 \dot{\varphi}_{1} \dot{\theta} \cos \left(\varphi_{1}\right)\right) \sin \left(\theta_{0}\right) \\
& \quad+\left(\dot{\varphi}_{2}^{2} \sin \left(\varphi_{2}\right)-\ddot{\varphi}_{2} \cos \left(\varphi_{2}\right)-\dot{\varphi}_{1}^{2} \sin \left(\varphi_{1}\right)+\ddot{\varphi}_{1} \cos \left(\varphi_{1}\right)\right) \cos \left(\theta_{0}\right) \\
& \quad+\left(-\ddot{\varphi}_{2} \varphi-2 \dot{\varphi}_{2}\right) \sin \left(\varphi_{2}\right)+\left(\ddot{\varphi}-\dot{\varphi}_{2}^{2} \varphi\right) \cos \left(\varphi_{2}\right) \\
& \left.\quad+\left(-\ddot{\varphi}_{1} \varphi-2 \dot{\varphi}_{\varphi_{1}}\right) \sin \left(\varphi_{1}\right)+\left(\ddot{\varphi}-\dot{\varphi}_{1}^{2} \varphi\right) \cos \left(\varphi_{1}\right)\right) \\
& =-\left(m_{k}+2 m_{w}\right) g+\sum_{i=1}^{n}\left(-k_{z} z_{C}+R_{\zeta_{i}} k_{z} \theta-R_{\xi_{i}} k_{z} \varphi-b_{z} \dot{z}_{C}+R_{\zeta_{i}} b_{z} \dot{\theta}-R_{\xi_{i}} b_{z} \dot{\varphi}\right)
\end{aligned}
$$

\section{Symulacja komputerowa ruchu podajnika}

Na podstawie wyprowadzonych równań przeprowadzono symulacje komputerowe ruchu przykładowego podajnika. Jego parametry fizyczne zamieszczono w tabeli 1. Silniki elektrowibratorów zamodelowano przy użyciu charakterystyki Klossa. Przyjęto:

- moment krytyczny (maksymalny) $M_{\mathrm{kr}}=3,0 \mathrm{Nm}$,

- prędkość synchroniczną $\omega_{\text {synch }}=157,1 \mathrm{rad} / \mathrm{s}$,

- prędkość krytyczną $\omega_{\mathrm{kr}}=125,6 \mathrm{rad} / \mathrm{s}$.

Pierwsze trzy rysunki (rys. 5-7) przedstawiają przebiegi współrzędnych uogólnionych w trakcie rozruchu podajnika i pracy ustalonej, przy czym po uzyskaniu prędkości roboczej wibratorów zasymulowano dodatkowo dwa zdarzenia. Pierwsze, przedstawiające istotny wzrost momentu desynchronizującego wibratory, który może być spowodowany np. zacieraniem się łożyska wibratora (druga sekunda symulacji), i drugie - usunięcie jednej ze sprężyn podparcia, czyli sytuację, która może się zdarzyć w przypadku złamania się sprężyny (trzecia sekunda symulacji). 
Tablela 1

Parametry fizyczne podajnika

\begin{tabular}{|c|c|c|}
\hline Oznaczenie & Wartość & Jednostka \\
\hline$m_{k}$ & 200,0 & $\mathrm{~kg}$ \\
\hline$m_{w}$ & 4,0 & $\mathrm{~kg}$ \\
\hline$e$ & 0,025 & $\mathrm{~m}$ \\
\hline$a$ & 0,25 & $\mathrm{~m}$ \\
\hline$h$ & 0,5 & $\mathrm{~kg}$ \\
\hline$J_{\xi}$ & 37,5 & $\mathrm{~kg} \cdot \mathrm{m}^{2}$ \\
\hline$J_{\eta}$ & 6,27 & $\mathrm{~kg} \cdot \mathrm{m}^{2}$ \\
\hline$J_{\zeta}$ & 37,5 & $\mathrm{~kg} \cdot \mathrm{m}^{2}$ \\
\hline$J_{\xi 1}$ & 0,0005 & $\mathrm{~kg} \cdot \mathrm{m}^{2}$ \\
\hline$J_{\zeta 1}$ & 0,001 & $\mathrm{~kg} \cdot \mathrm{m}^{2}$ \\
\hline$\theta_{0}$ & 30,0 & $\mathrm{deg}$ \\
\hline$k_{x}$ & 4105,0 & $\mathrm{~N} / \mathrm{m}$ \\
\hline$k_{y}$ & 4105,0 & $\mathrm{~N} / \mathrm{m}$ \\
\hline$k_{z}$ & 16423,0 & $\mathrm{~N} / \mathrm{m}$ \\
\hline$b_{x}$ & 36,96 & $\mathrm{Ns} / \mathrm{m}$ \\
\hline$b_{y}$ & 36,96 & $\mathrm{Ns} / \mathrm{m}$ \\
\hline$b_{z}$ & 73,92 & $\mathrm{Ns} / \mathrm{m}$ \\
\hline$n$ & 8 & - \\
\hline
\end{tabular}

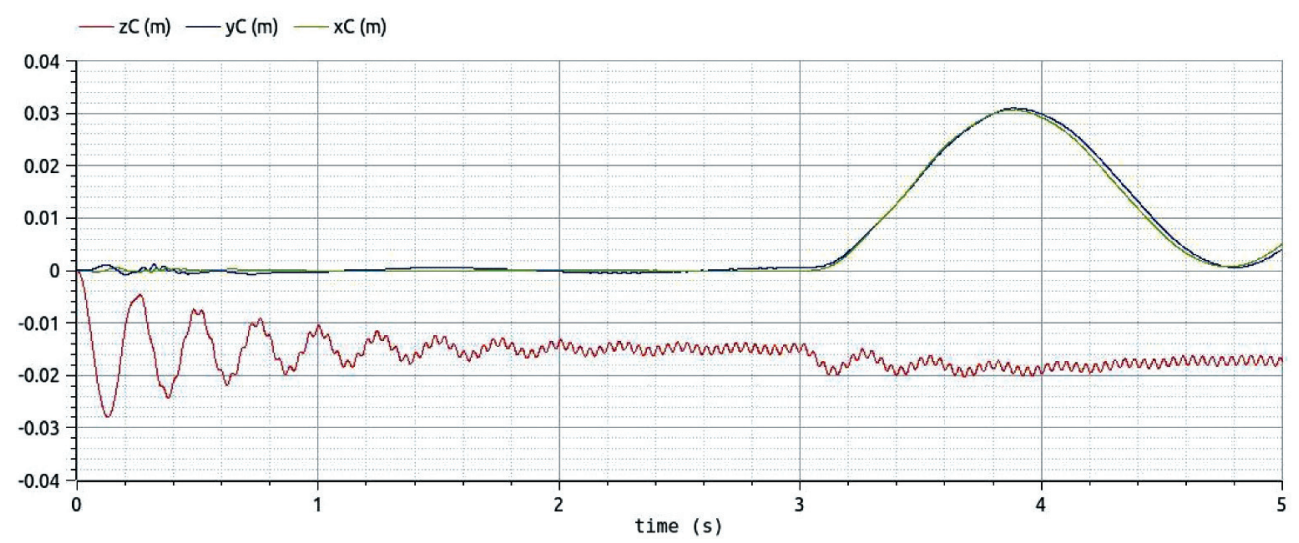

Rys. 5. Przebiegi współrzędnych $x_{C}, y_{C}, z_{C}$ środka masy korpusu podajnika 


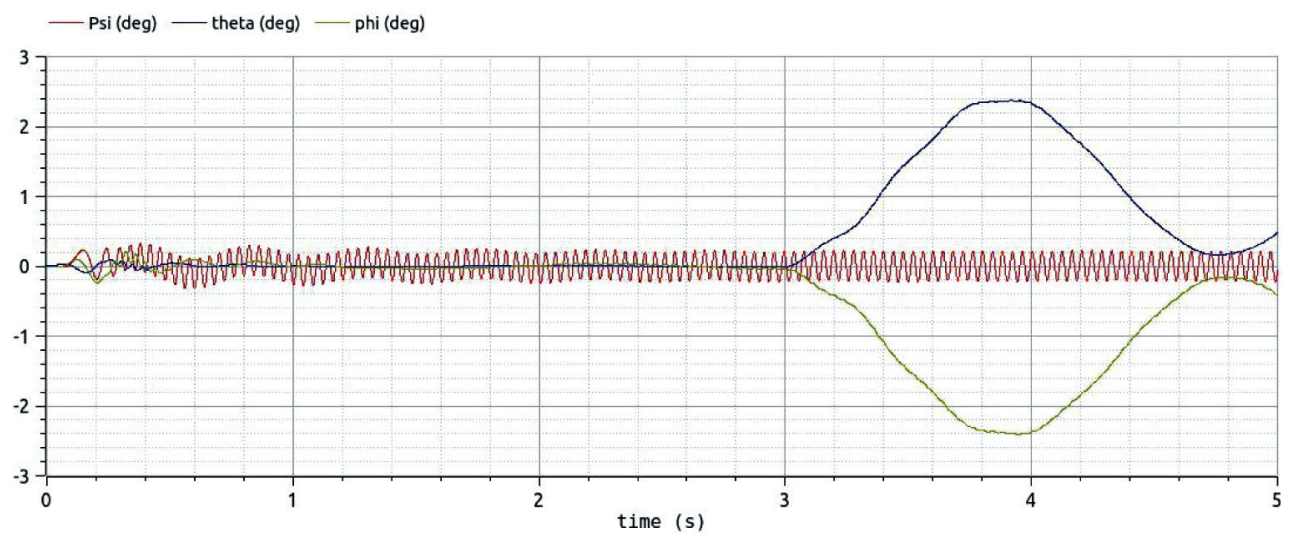

Rys. 6. Przebiegi kątów obrotu korpusu przenośnika $\Psi, \theta, \varphi$

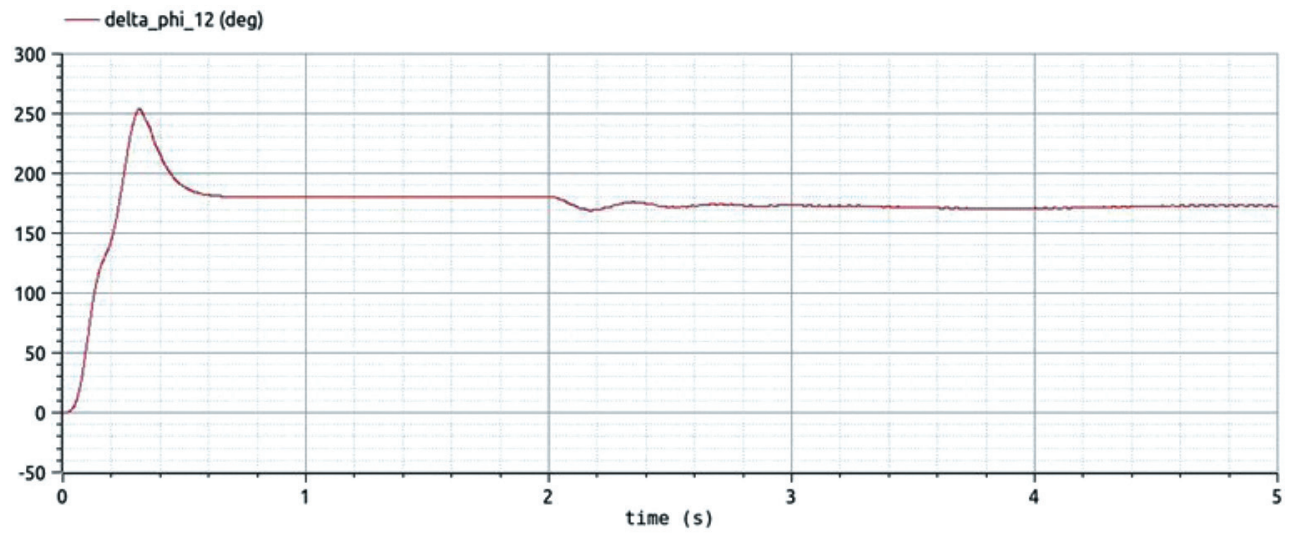

Rys. 7. Przebieg procesu synchronizacji wibratorów $\varphi_{2}-\varphi_{1}$

Kolejne cztery rysunki (rys. 8-11) przedstawiają symulację przebiegu procesu desynchronizacji wibratorów w wyniku znaczącego wzrostu momentu desynchronizującego. Jego wartość została dwukrotnie zmieniona: z $0 \mathrm{Nm}$ do 1,0 Nm w pierwszej sekundzie symulacji i z 1,0 Nm do $1,2 \mathrm{Nm}$ w trzeciej sekundzie symulacji. Jak można zauważyć, przekroczenie wartości $1.0 \mathrm{Nm}$ powoduje utratę więzi synchronicznej wibratorów (por. rys. 10) i wystąpienie charakterystycznych dudnień korpusu przenośnika (por. rys. 11), prowadząc do zaburzeń pożądanego ruchu nadawy.

Zgodnie z zasadą ruchu środka masy oraz drugim prawem Newtona można przy założeniu znikomego oddziaływania zawieszenia na ruch korpusu podajnika (sytuacja taka ma miejsce w zakresie pracy nadrezonansowej) wyznaczyć zależności szacunkowe 
na amplitudę drgań środka masy przenośnika (wzór (17)) oraz amplitudę drgań kątowych względem osi $\eta$ ) (wzór (18)).

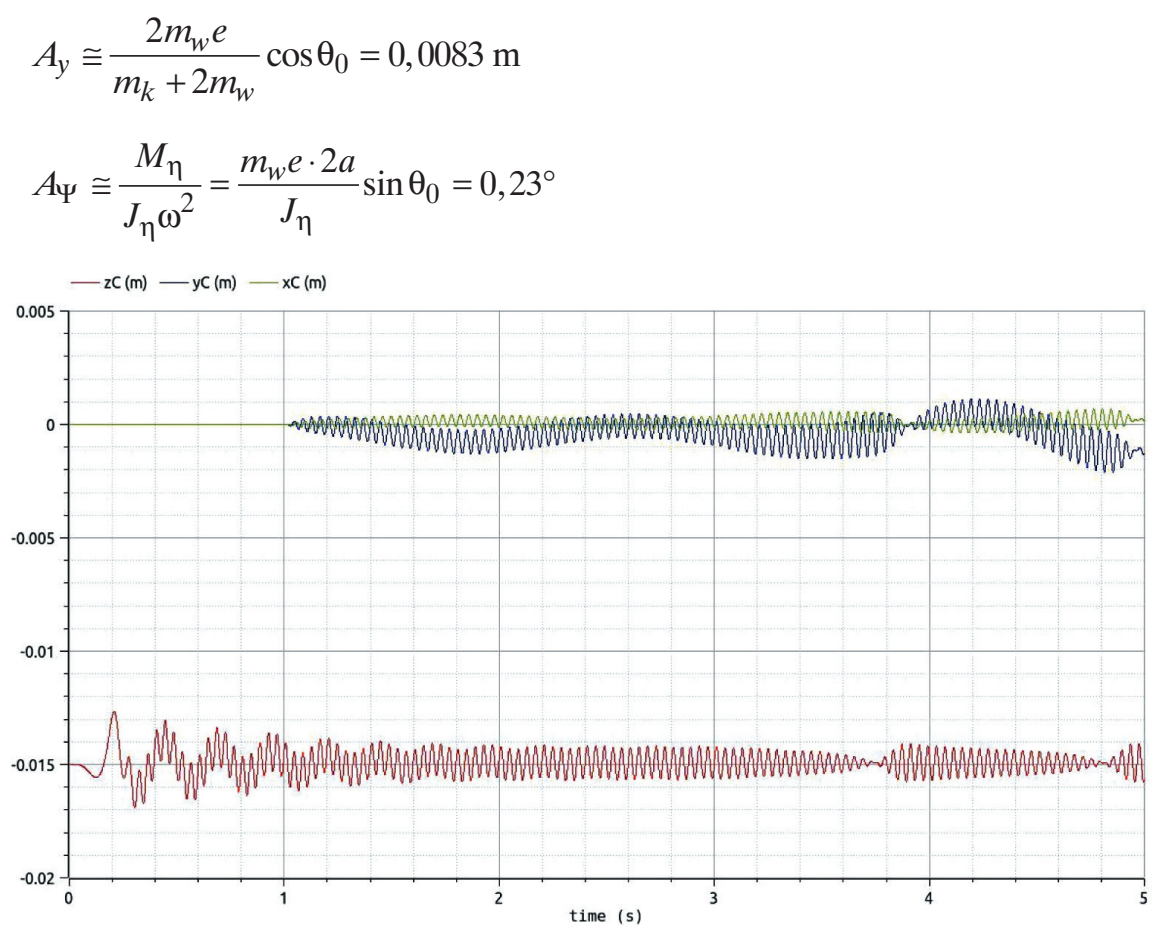

Rys. 8. Przebiegi współrzędnych $x_{C}, y_{C}, z_{C}$ środka masy korpusu podajnika w przypadku znaczącego wzrostu momentu desynchronizującego

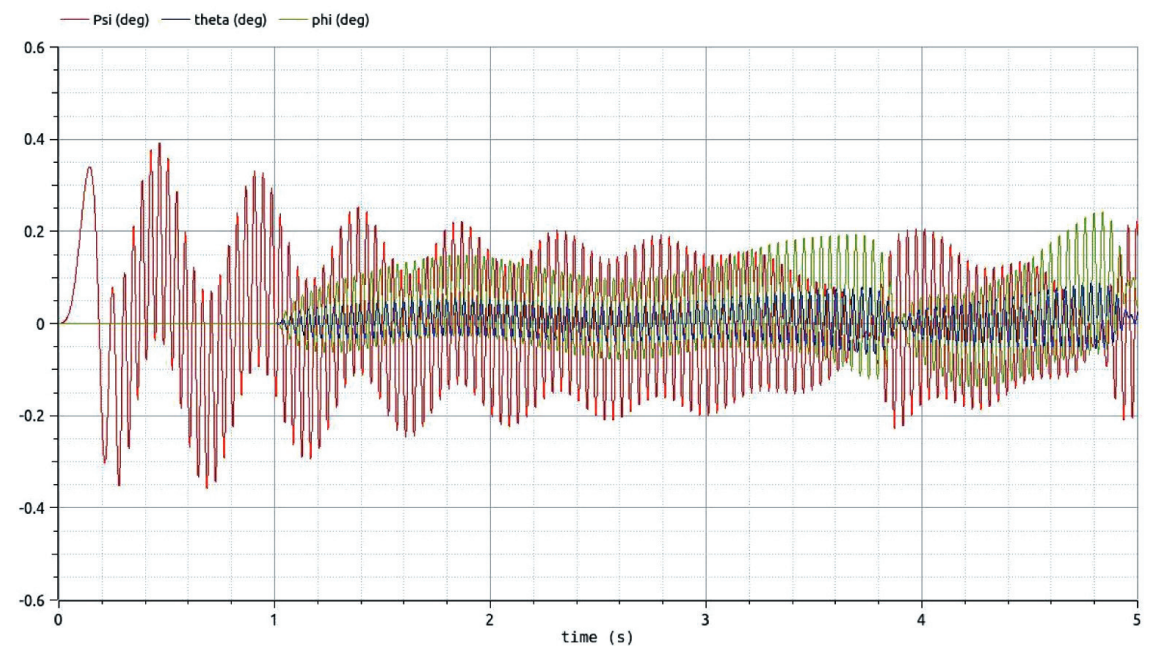

Rys. 9. Przebiegi kątów obrotu korpusu przenośnika $\Psi, \theta, \varphi$ w przypadku znaczącego wzrostu momentu desynchronizującego 


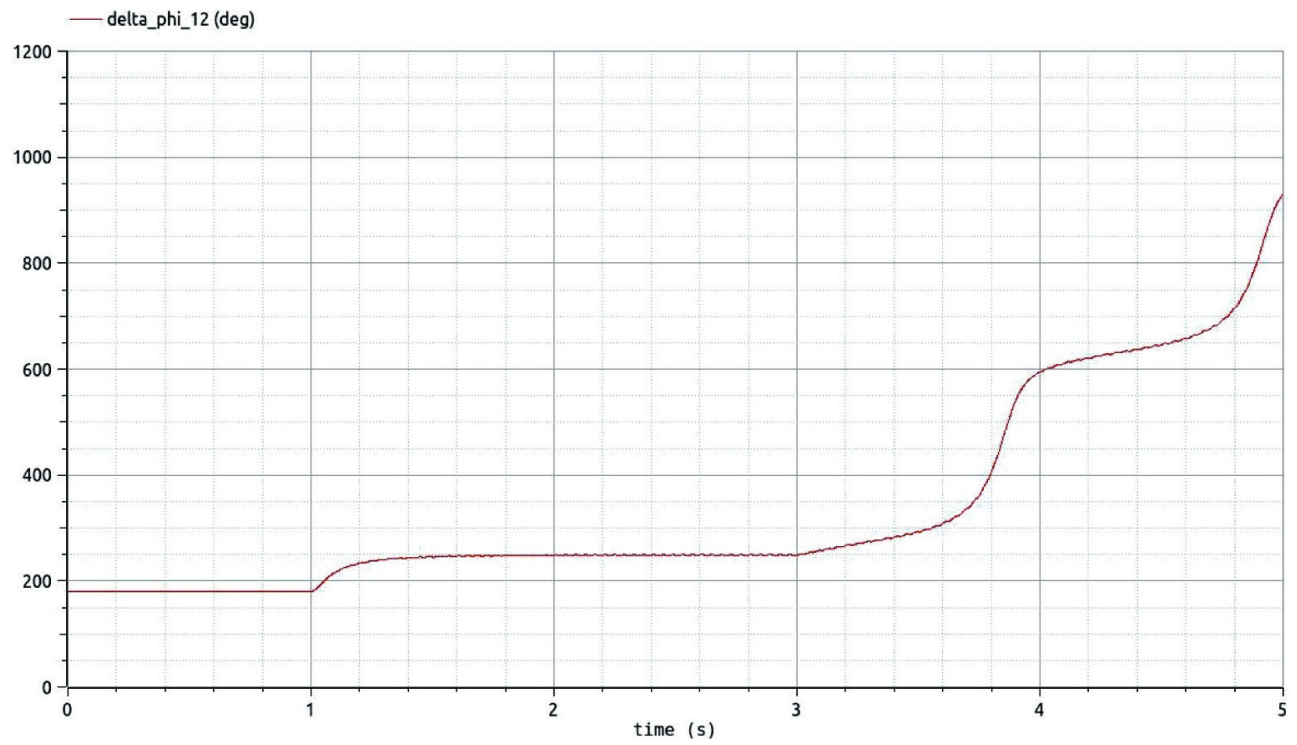

Rys. 10. Przebieg procesu synchronizacji wibratorów: $\varphi_{2}-\varphi_{1}$ w przypadku znaczącego wzrostu momentu desynchronizującego

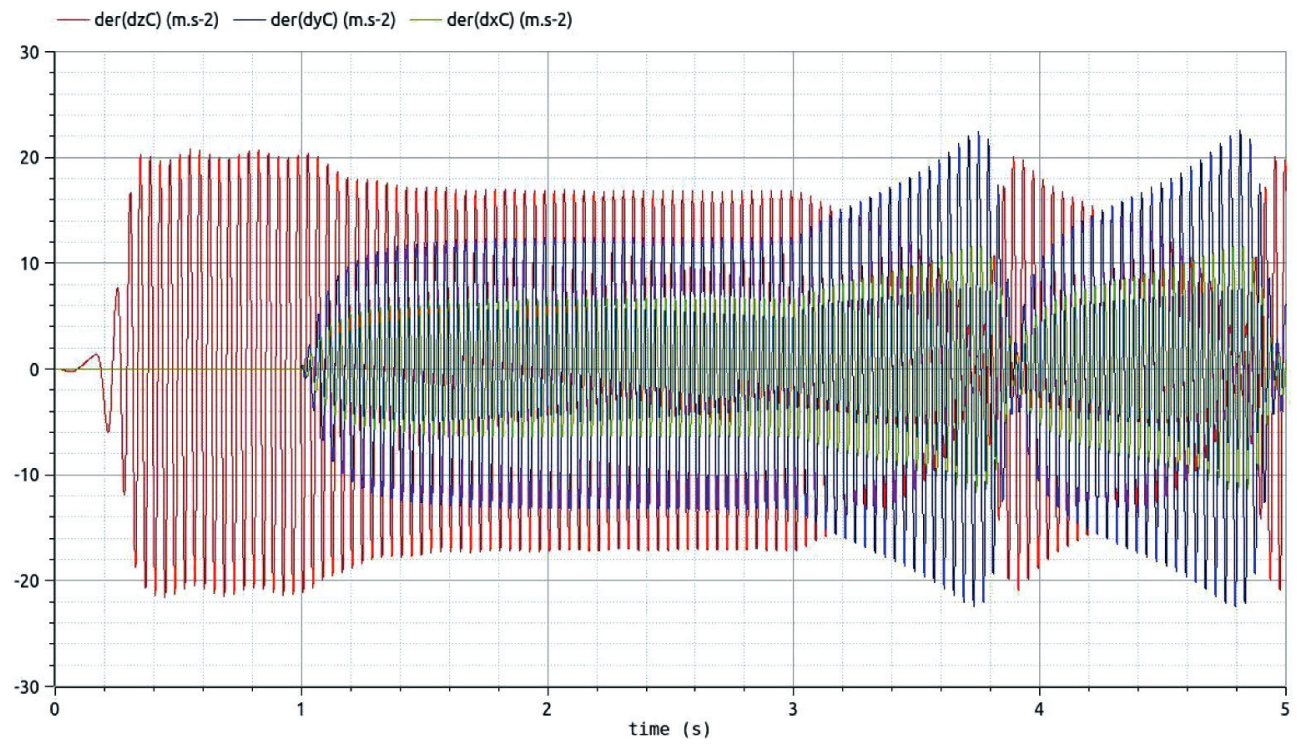

Rys. 11. Przebiegi przyspieszeń $x_{C}, y_{C}, z_{C}$ środka masy korpusu podajnika w przypadku znaczącego wzrostu momentu desynchronizującego

Jak można zauważyć, wartości tych amplitud są w zgodzie z wartościami symulacji komputerowych (rys. 12), co w istotny sposób weryfikuje poprawność tego modelu. 

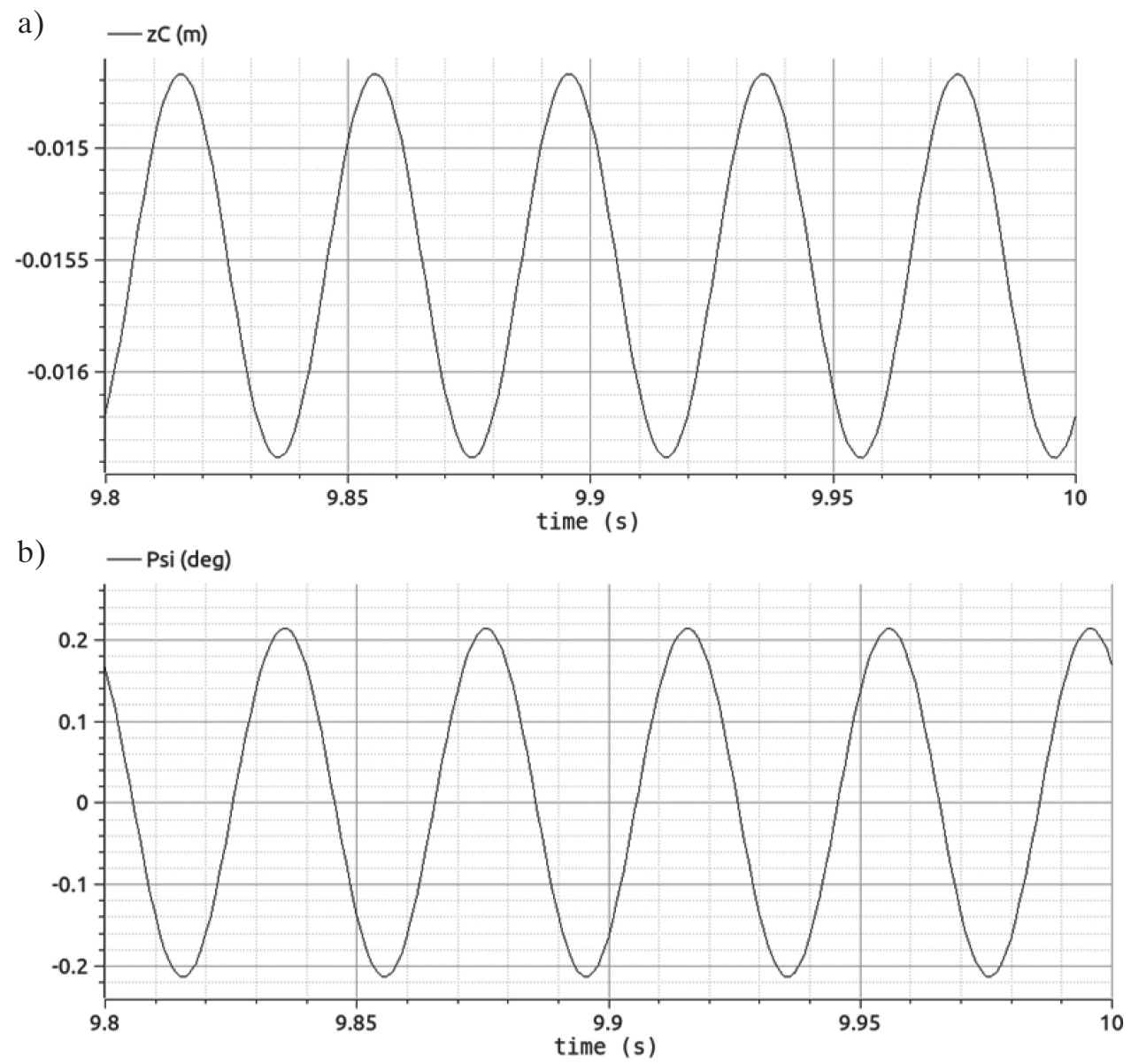

Rys. 12. Przebiegi wybranych współrzędnych podajnika w stanie pracy ustalonej: a) przebieg współrzędnej $z_{C}$ środka masy podajnika; b) przebieg współrzędnej $\Psi$ korpusu podajnika

\section{Podsumowanie}

Celem pracy było zbudowanie modelu przestrzennego spiralnego podajnika wibracyjnego mogącego uwzględnić dynamikę stanów przejściowych maszyny w trakcie jej rozruchu i wybiegu oraz analizę stanu ustalonego. Model uwzględnia wzajemne oddziaływanie mas wibratorów i korpusu, dzięki czemu umożliwia odzwierciedlenie, niezwykle ważnego dla prawidłowej pracy podajnika, procesu samosynchronizacji wibratorów. Ze względu na daleko posuniętą parametryzację umożliwia modelowanie zachowań awaryjnych, np. wynikających z pojawienia się niesymetrii w zawieszeniu sprężystym. Może stanowić punkt wyjścia do prac związanych z wyznaczeniem anali- 
tycznych zależności na wartość momentu synchronizującego (po uprzednim uproszczeniu równań do postaci liniowej) oraz zależności analitycznych na amplitudy współrzędnych opisujących ruch korpusu podajnika w stanie ustalonym - dwie takie zależności zostały przedstawione w pracy. Uproszczona liniowa forma równań może ułatwić wyznaczenie wszystkich sześciu częstości drgań własnych podajnika niezwykle istotnych ze względu na niebezpieczeństwo pojawienia się rezonansów stacjonarnych przy nazbyt wysoko nastrojonym zawieszeniu.

Zaprezentowany model stanowi podstawę teoretyczną do prac prowadzonych w Laboratorium Mechaniki i Dynamiki Maszyn na Wydziale Inżynierii Mechanicznej i Robotyki AGH związanych z projektowaniem i eksploatacją pionowych podajników wibracyjnych.

\section{Literatura}

Bayıroğlu H., 2015, Nonlinear analysis of unbalanced mass of vertical conveyer with nonideal exciters, Applied Mechanics and Materials, vol. 706, s. 35-43. https:// doi.org/10.4028/www.scientific.net/AMM.706.35.

Cieplok G., Wójcik K., 2020, Conditions for self- synchronization of inertial vibrators of vibratory conveyors in general motion, Journal of Theoretical and Applied Mechanics, vol. 58, no. 2, s. 513-524. https://doi.org/10.15632/jtam-pl/119023.

Czubak P., 2013, Wybrane zagadnienia dynamiki przenośników wibracyjnych, Wydawnictwa AGH, Kraków.

Hamed Y.S., Sayed M., El-Awad R.A., 2017, On controlling the nonlinear response of vibrational vertical conveyor under mixed excitation, Global Journal of Pure and Applied Mathematics, vol. 13, no. 9, s. 6493-6509.

Michalczyk K., Bera P., 2019, A simple formula for predicting the first natural frequency of transverse vibrations of axially loaded helical springs, Journal of Theoretical and Applied Mechanics, vol. 57, iss. 3, s. 779-790. https://doi.org/10.15632/jtam-pl/110243.

Michalczyk J., Cieplok G., Bednarski Ł., 2006, Forcing the startup of vibratory machines by means of small power motors, Archive of Mechanical Engineering, vol. 53, no. 4, s. 379-395.

Sikora W., Michalczyk K., Machniewicz T., 2018, Numerical modelling of metal-elastomer spring nonlinear response for low-rate deformations, Acta Mechanica et Automatica, vol. 12, no. 1, s. 31-37. https://doi.org/10.2478/ama-2018-0005.

Su J., Jie T., Yanhu S., 2019, Analysis of amplitude-frequency characteristics of spiral vibrating feeder system, IOP Conference Series: Materials Science and Engineering, vol. 612, no. 3, 032155. https://doi.org/10.1088/1757-899x/612/3/032155. 